\title{
Bronchodilator response to salbutamol after spontaneous recov- ery from nonspecific bronchial provocation tests in asthma
}

\author{
R. Polosa, G. Prosperini, S. Magrì, I. Ciamarra, C. Pagano, G. Paolino, G. Santonocito, N. Crimi
}

Bronchodilator response to salbutamol after spontaneous recovery from nonspecific bronchial provocation tests in asthma. R. Polosa, G. Prosperini, S. Magrì, I. Ciamarra, C. Pagano, G. Paolino, G. Santonocito, N. Crimi. CERS Journals Ltd 1998.

ABSTRACT: Assessment of airway responsiveness by bronchoprovocation and bronchodilatation tests is important in the diagnostic work-up protocol of bronchial asthma and it would be convenient to undertake both tests on the same occasion. However, it is not known whether this can be done accurately. Therefore, this study evaluated the effect of a prior bronchial provocation test on the bronchodilator response to salbutamol after spontaneous recovery of the forced expiratory volume in one second (FEV1) in a group of asthmatic subjects.

On two separate occasions at the same time of day, concentration-response studies with inhaled histamine or methacholine, or a sham challenge with normal saline were carried out in a blinded, randomized manner. Changes in airway calibre were followed as FEV1 and agonist responsiveness expressed as the provocative concentration causing a $20 \%$ fall in FEV1 (PC20). After either spontaneous recovery or a fixed-duration wait of $45 \mathrm{~min}$ (when appropriate), the subjects received $2 \times 100 \mu \mathrm{g}$ of salbutamol from a metered dose inhaler with a spacer. The bronchodilator response to salbutamol was expressed as a percentage of initial FEV1 $(\triangle \mathrm{FEV} 1 \%$ init).

Bronchial challenge with both agonists failed to alter significantly the airway response to salbutamol, with the $\triangle \mathrm{FEV} 1 \%$ init mean value (range) being $16.9 \%(9.0$ 31.9) and $17.5 \%(11.6-31.2)$ on the sham and histamine/methacholine challenge day respectively.

It was shown that the degree of bronchodilatation achieved after salbutamol $200 \mu \mathrm{g}$ is not affected by prior bronchoprovocation testing when enough time is allowed for the airways to recover spontaneously to baseline forced expiratory volume in one second. Thus evaluation of airway responsiveness by both bronchial provocation tests and bronchodilator testing can be assessed reliably within a few hours in asthmatic patients. Eur Respir J 1998; 11: 1086-1090.
Istituto Malattie Apparato Respiratorio, Universita' di Catania, Italy.

Correspondence: R. Polosa

Istituto Malattie Apparato Respiratorio

Universita' di Catania

Via Passo Gravina 187

95125 Catania

Italy

Fax: 3995330707

Keywords: Asthma

bronchoconstriction

bronchodilatation

salbutamol

Received: January 291997

Accepted after revision September 151997
Evaluations of airway responsiveness to bronchodilatory drugs such as salbutamol and to spasmogenic agonists such as histamine or methacholine are routine procedures in pulmonary function laboratories. These tests may play an important role in the diagnosis and clinical assessment of bronchial asthma as well as in pulmonary research [1]. Since both reversibility of airflow obstruction and degree of airway responsiveness are known to be objective indicators of asthma severity [1,2], it would be convenient if they could be carried out on the same visit to the pulmonary function laboratory.

However, combining a bronchodilator response and a bronchoprovocation test on the same occasion might provide inaccurate results. It is widely acknowledged that short-acting $\beta_{2}$-agonists administered prior to bronchoprovocation provide functional antagonism against a wide variety of bronchoconstrictor stimuli (including histamine and methacholine) for up to 4-6 h [3-5], but little is known about the effect of histamine or methacholine bronchoconstriction on a subsequent bronchodilator response to inhaled $\beta_{2}$-agonists. It is possible that exposure to spasmogenic agents such as histamine and methacholine may affect the subsequent response to an inhaled $\beta_{2}$-agonist even after airway calibre has returned to baseline. Al-though the forced expiratory volume in one second (FEV1) recovers rapidly after exposure to histamine or methacho-line [6], these agonists may elicit changes in bronchial blood flow that may persist well beyond the recorded changes in their spirometric values [7-9]. This may therefore increase the transepithelial clearance of subsequently administered $\beta_{2}$-agonists and affect their efficacy.

Therefore this study was undertaken to investigate the effect of bronchial provocation testing on subsequent bronchodilator responses to inhaled salbutamol after spontaneous recovery of FEV1 to the prechallenge level in subjects with asthma. Evaluation of airway responsiveness by combining a bronchodilator response and a bronchial provocation test on the same occasion was shown to provide accurate results.

\section{Methods}

\section{Subjects}

Twenty four patients (16 females and 8 males), mean age $29.8 \pm 1.7$ yrs ( \pm SEM), selected from chest clinics with 
Table 1. - Demographic details of the subjects

\begin{tabular}{|c|c|c|c|c|c|c|}
\hline $\begin{array}{l}\text { Subject } \\
\text { no. }\end{array}$ & Sex & $\begin{array}{l}\text { Age } \\
\text { yrs }\end{array}$ & $\begin{array}{c}\text { Baseline FEV } 1 \\
\% \text { pred }\end{array}$ & $\begin{array}{c}\text { PC20 histamine } \\
\mathrm{mg} \cdot \mathrm{mL}^{-1}\end{array}$ & $\begin{array}{c}\mathrm{PC} 20 \\
\text { methacholine } \\
\mathrm{mg} \cdot \mathrm{mL}^{-1}\end{array}$ & $\begin{array}{l}\text { Recovery time } \\
\text { min }\end{array}$ \\
\hline$\overline{1}$ & $\mathrm{~F}$ & 25 & 63 & 0.17 & - & 45 \\
\hline 2 & $\mathrm{~F}$ & 26 & 83 & 2.39 & - & 45 \\
\hline 3 & $\mathrm{M}$ & 28 & 90 & 3.71 & - & 60 \\
\hline 4 & $\mathrm{M}$ & 29 & 84 & 0.57 & - & 45 \\
\hline 5 & $\mathrm{~F}$ & 44 & 84 & 4.92 & - & 45 \\
\hline 6 & M & 35 & 84 & 4.08 & - & 45 \\
\hline 7 & $\mathrm{~F}$ & 38 & 85 & 0.40 & - & 30 \\
\hline 8 & $\mathrm{M}$ & 20 & 75 & 1.50 & - & 45 \\
\hline 9 & $\mathrm{~F}$ & 25 & 76 & 2.22 & - & 60 \\
\hline 10 & $\mathrm{M}$ & 30 & 80 & 2.20 & - & 60 \\
\hline 11 & $\mathrm{~F}$ & 18 & 73 & 1.13 & - & 30 \\
\hline 12 & $\mathrm{~F}$ & 29 & 77 & 1.70 & - & 45 \\
\hline 13 & $\mathrm{~F}$ & 40 & 77 & 1.77 & - & 60 \\
\hline 14 & $\mathrm{~F}$ & 41 & 79 & 1.20 & - & 45 \\
\hline 15 & $\mathrm{M}$ & 32 & 88 & - & 2.69 & 90 \\
\hline 16 & $\mathrm{~F}$ & 28 & 85 & - & 3.01 & 75 \\
\hline 17 & $\mathrm{~F}$ & 21 & 79 & - & 1.57 & 60 \\
\hline 18 & $\mathrm{~F}$ & 23 & 81 & - & 0.50 & 45 \\
\hline 19 & $\mathrm{~F}$ & 47 & 87 & - & 1.59 & 60 \\
\hline 20 & $\mathrm{M}$ & 16 & 83 & - & 2.08 & 60 \\
\hline 21 & $\mathrm{~F}$ & 32 & 68 & - & 1.16 & 90 \\
\hline 22 & M & 34 & 75 & - & 0.79 & 45 \\
\hline 23 & $\mathrm{~F}$ & 25 & 82 & - & 3.77 & 90 \\
\hline 24 & $\mathrm{~F}$ & 28 & 67 & - & 2.01 & 60 \\
\hline Mean & & 29.8 & 79.4 & $1.46^{*}$ & $1.65^{*}$ & \\
\hline SEM & & \pm 1.7 & \pm 1.4 & $(0.17-4.92)$ & $(0.50-3.77)$ & \\
\hline
\end{tabular}

*: geometric mean (range); FEV1: forced expiratory volume in one second; PC20: provocative concentration producing a $20 \%$ fall in FEV1; M: male; F: female.

stable asthma as defined by the American Thoracic Society [1], participated in the study (table 1). All subjects had a history of dyspnoea with wheezing or chest tightness and were nonsmokers with positive skin-prick tests $(>3 \mathrm{~mm}$ weal response) to one or more of six common aeroallergens (Dermatophagoides pteronyssinus, Dermatophagoides farinae, Parietaria sp. pollens, mixed grass pollens, cat fur and dog hair). At the beginning of the study the baseline FEV1 of all subjects was at least $60 \%$ of the predicted values. None had been receiving steroids, theophylline or antihistamines within the preceding 4 weeks. Inhaled bronchodilators were discontinued for at least $8 \mathrm{~h}$ before each visit to the laboratory. Subjects were not studied within 4 weeks of an upper respiratory tract infection or exacerbation of their asthma and all visits to the laboratory were carried out at the same time of day and outside the pollen season. Additional criteria for inclusion were a provocative concentration of histamine or methacholine reducing FEV1 by $20 \%$ (PC20) of $<8 \mathrm{mg} \cdot \mathrm{mL}^{-1}$ and a bronchodilator response to standard salbutamol of at least $12 \%$ from initial FEV1 [10]. The study was approved by the Ethical Committee of the University of Catania, and all subjects gave their informed consent.

\section{Bronchial provocation}

Airway calibre was recorded as the FEV1 using a dry wedge spirometer (Vitalograph, Buckinghamshire, UK), with the better of two consecutive measurements being recorded.
Histamine acid phosphate (Sigma Chemical Co., St Louis, MO, USA) was dissolved in $0.9 \%(\mathrm{w} / \mathrm{v})$ sodium chloride to produce a stock solution of $16 \mathrm{mg} \cdot \mathrm{mL}^{-1}$. In eight of the subjects studied, methacholine instead of histamine was used. Methacholine (Sigma Chemical Co.,) was freshly prepared in $0.9 \%(\mathrm{w} / \mathrm{v})$ sodium chloride to produce stock solutions of $32 \mathrm{mg} \cdot \mathrm{mL}^{-1}$. Each stock solution was then diluted with $0.9 \%(\mathrm{w} / \mathrm{v})$ sodium chloride to produce a concentration range of $0.03-8 \mathrm{mg} \cdot \mathrm{mL}^{-1}$ for histamine and $0.03-16 \mathrm{mg} \cdot \mathrm{mL}^{-1}$ for methacholine.

The solutions were administered as aerosols generated from a starting volume of $3 \mathrm{~mL}$ in a disposable Inspiron Mini-nebulizer (C.R. Bard International, Sunderland, UK) driven by compressed air at $8 \mathrm{~L} \cdot \mathrm{min}^{-1}$. Under these conditions the nebulizer had an output of $0.48 \mathrm{~mL} \cdot \mathrm{min}^{-1}$ and generated an aerosol with a mass median particle diameter of $4.7 \mu \mathrm{m}$ [11]. Subjects inhaled the aerosolized solutions in five breaths from end-tidal volume to full inspiratory capacity via a mouthpiece, as described by Снал et al. [12]. Subjects were trained to take $3 \mathrm{~s}$ to reach full inspiratory capacity.

\section{Bronchodilator response}

FEV1 was measured with a dry wedge spirometer (Vitalograph) connected to an Apple microcomputer. The best of three technically satisfactory FEV1 measurements was recorded, expressed as a percentage of the predicted value and used for subsequent analysis. The bronchodilation test 
was carried out by administering inhaled salbutamol according to a standardized protocol [10]. Two puffs of salbutamol $\left(100 \mu \mathrm{g} \cdot\right.$ puff $\left.^{-1}\right)$ were given from a metered dose inhaler with a spacer device (Aerochamber). Salbutamol was inhaled during a single, slow inspiration from functional residual capacity to total lung capacity immediately after each actuation. The breath was then held for about $10 \mathrm{~s}$ before exhalation. A second actuation was then repeated and FEV1 recorded 20 min later. The bronchodilator res-ponse to salbutamol was expressed as a percentage of initial FEV1 ( $\triangle \mathrm{FEV} 1 \%$ init) [10].

\section{Study design}

The subjects were selected on two separate days. On the first occasion skin testing, spirometry and bronchial challenge were performed. On the second visit they underwent a standardized bronchodilatation test at the lung function laboratory. After inclusion, the subjects entered a single-blind, randomized, cross-over study consisting of two separate visits 3-7 days apart, during which a bronchodilator test with salbutamol was preceded by a bronchial provocation test with inhaled histamine or methacholine, or normal saline (sham challenge). To minimize bias, statistical analysis was carried out by an independent investigator.

On the first visit, subjects underwent concentrationresponse studies with inhaled histamine (except for subjects no. 15-24, who were given methacholine). After 15 min rest, three baseline measurements of FEV1 were made at intervals of $3 \mathrm{~min}$ followed by inhalation of $0.9 \%$ (w/v) sodium chloride and further FEV1 measurements repeated at 1 and $3 \mathrm{~min}$. Provided FEV1 had not fallen by $>10 \%$ of the baseline value, a histamine or methacholine concentration-response study was carried out. After administration of each concentration of the agonist, FEV1 was measured at 1 and $3 \mathrm{~min}$. Increasing doubled concentrations of histamine or methacholine were inhaled at intervals of 5 min until FEV1 had fallen by $>20 \%$ of the post-saline baseline value and the corresponding PC20 values had been derived. Following the bronchoprovocation test, the airways were allowed to recover spontaneously, until FEV1 had returned to within $5 \%$ of the post-saline baseline value. On achieving this, after approximately 30 $90 \mathrm{~min}$, a bronchodilator test with inhaled salbutamol $(200 \mu \mathrm{g})$ was then undertaken, and the FEV1 value recorded 20 min later.

On the second visit, all the subjects studied underwent a sham challenge with inhaled normal saline to maintain blindness. In brief, three solutions of normal saline were nebulized at intervals of approximately $5 \mathrm{~min}$ and the subsequent bronchodilator test with inhaled salbutamol was carried out after $45 \mathrm{~min}$ in the manner described above.

\section{Data analyses}

Values refer to the mean \pm SEM unless otherwise stated, and a p-value of $<0.05$ was accepted as significant. Preand post-challenge baseline values of FEV1 prior to the bronchodilator test were compared between and within study days by two-factor analysis of variance (ANOVA) followed by the Neuman-Keuls test where appropriate.
Concentration-response curves were constructed by plotting the percentage change in FEV 1 from the post-saline baseline value against the cumulative concentration of the agonist administered on a logarithmic scale and the PC20 determined by linear interpolation. PC20 values were log transformed prior to analysis.

Repeatability of bronchodilatation testing was assessed according to the method of ALTMAN and BLAND [13] by deriving the standard deviation of the differences between the $\Delta \mathrm{FEV}_{1} \%$ init values obtained at the inclusion in the study and those obtained on the sham challenge day. The coefficient of repeatability $(\mathrm{CR})$ is twice this standard de-viation.

The response to the bronchodilator obtained on the two study days was expressed as $\triangle \mathrm{FEV} 1 \%$ init and compared using the Student's t-test for paired data. Any relationship between $\triangle \mathrm{FEV} 1 \%$ init and airway responses to histamine or methacholine ( $\log$ PC20) was examined by least-squares linear regression analysis. The bronchodilator response in subjects challenged with histamine was compared with that in subjects challenged with methacholine using the Mann-Whitney U-test.

The probability of a Type II error $(\beta)$ was assessed, that is, the risk of wrongly accepting the null hypothesis of absence of difference in bronchodilation between the two study days. Thus, the power of the test to detect change was calculated. Power calculations, based on the assumption that a significant change in the $\triangle \mathrm{FEV} 1 \%$ init is approximately $3 \%$, indicated for the 24 subjects studied that there was a $85 \%$ chance of detecting a significant difference with a significance level of $<5 \%$ (two-sided).

\section{Results}

Of the 30 consecutive subjects who entered the study, five did not complete the study because FEV1 recordings on the second study day differed by more than $10 \%$ from those on the first day and one because he repeatedly failed to attend his appointment. Thus, a total of 16 women and eight men completed the study (table 1).

There was no statistically significant change between baseline FEV1 values obtained on the two study days. After bronchoprovocation, FEV1 had spontaneously returned to within $5 \%$ of the baseline values in all of the subjects studied in 90 min (table 1).

The bronchodilator response to salbutamol in this group of subjects was found to be repeatable, with a CR of $6.4 \%$. The differences between the $\triangle \mathrm{FEV} 1 \%$ init values obtained at the inclusion in the study and those obtained on the sham challenge day were within $6.4 \%$ in 23 out of 24 subjects receiving salbutamol.

Twenty min after the administration of $200 \mu \mathrm{g}$ salbutamol, FEV1 obtained on the histamine or methacholine challenge day was not significantly different from that obtained on the control challenge day. $\triangle \mathrm{FEV} 1 \%$ init after $200 \mu \mathrm{g}$ salbutamol on the agonist study day was $17.5 \%$, while that on the control challenge day was $16.9 \%$ (table 2).

There was no statistically significant relationship between $\triangle \mathrm{FEV} 1 \%$ init and airway responses to histamine or methacholine ( $\log \mathrm{PC} 20)$. Finally, no significant difference was detected when $\triangle \mathrm{FEV} 1 \%$ init values were analysed separately for histamine and methacholine. 
Table 2. - Effect of previous bronchoprovocation test on bronchodilator response

\begin{tabular}{lccc}
\hline & \multicolumn{3}{c}{$\Delta$ FEV $\%$ init } \\
\cline { 2 - 4 } Subject no. & Baseline & Post-control & Post-agonists* \\
\hline 1 & 25.0 & 31.9 & 26.6 \\
2 & 19.7 & 16.3 & 14.3 \\
3 & 13.3 & 12.7 & 12.4 \\
4 & 12.5 & 17.7 & 13.3 \\
5 & 14.9 & 9.0 & 12.3 \\
6 & 15.1 & 12.1 & 11.6 \\
7 & 16.3 & 12.0 & 13.2 \\
8 & 12.0 & 13.5 & 14.2 \\
9 & 14.4 & 17.6 & 21.2 \\
10 & 12.0 & 14.5 & 12.0 \\
11 & 18.6 & 17.8 & 30.0 \\
12 & 15.1 & 17.4 & 18.9 \\
13 & 14.0 & 15.7 & 14.7 \\
14 & 14.9 & 18.8 & 18.4 \\
15 & 21.0 & 24.6 & 20.7 \\
16 & 18.8 & 18.7 & 22.4 \\
17 & 15.5 & 17.7 & 13.0 \\
18 & 12.2 & 13.1 & 16.2 \\
19 & 12.0 & 13.5 & 14.2 \\
20 & 17.7 & 14.9 & 12.5 \\
21 & 22.2 & 18.0 & 20.0 \\
22 & 17.0 & 14.5 & 18.6 \\
23 & 18.0 & 19.5 & 18.0 \\
24 & 25.7 & 24.0 & 31.2 \\
Mean & 16.6 & 16.9 & 17.5 \\
SEM & \pm 0.7 & \pm 1.0 & \pm 1.2 \\
\hline & & &
\end{tabular}

*: subjects $1-14$, bronchoprovocation test with histamine; $15-$ 24 , bronchoprovocation test with methacholine. $\triangle \mathrm{FEV} 1 \%$ init: percentage of the initial forced expiratory volume in one second.

\section{Discussion}

Although it has been suggested that pulmonary function tests can be accurately performed after a histamine challenge when FEV1 has returned to $95 \%$ of the baseline value $[14,15]$, the effect of a prior bronchial provocation test with nonspecific agonists on subsequent bronchodilator response to salbutamol has not been thoroughly elucidated. This is important in order to assess the validity of performing the two tests on the same occasion. The findings of the present study have shown that, when compared to sham challenge, the bronchodilator response to salbutamol is unaffected by prior bronchoprovocation test with histamine and/or methacholine when spontaneous recovery to baseline spirometry is allowed. This result is independent of the agonist used in bronchoprovocation testing. Thus, the evaluation of airway responsiveness by combining a bronchodilator response and a bronchial provocation test on the same occasion provides accurate results. Similar conclusions have been obtained in children with stable asthma [16].

Airway obstruction caused by spasmogenic stimuli is the result of a complex process in which airway smooth muscle shortening and oedema of the airway wall due to increased post-capillary venular leakage are thought to be predominant [7-9]. In theory, a thickened mucosa and submucosa and altered volume and properties of airway secretions may affect the availability of the $\beta_{2}$-agonists to their related receptors, limiting or delaying the bronchodilator response even in presence of restored baseline respiratory function. The present findings that bronchodilatation with $\beta_{2}$-agonists remains unaffected by prior bronchoprovocation tests with nonspecific agonists clearly indicate that the above-mentioned mechanisms are not important. However, timing of administration of the $\beta_{2-}$ agonist after challenge and its dosage may have influenced the bronchodilator response. Merkus et al. [16] have shown that this may be a possibility. Indeed, when $800 \mu \mathrm{g}$ salbutamol was administered instead of $400 \mu \mathrm{g}$, no effect of prior bronchoprovocation with histamine challenge was observed.

No significant difference was detected when $\triangle \mathrm{FEV}_{1} \%$ init values were analysed separately for histamine and methacholine. When results were examined separately for histamine and methacholine, similar falls in FEV1 values from baseline were reported, thus excluding any potential agonist-related effect (or lack of effect). This again confirms the view that even if the action of agonists is perpetuated on the airway structures for longer than their action on the calibre of the large airways, this does not affect subsequent changes in airway calibre after inhaled salbutamol when assessed as FEV1.

Bronchial hyperresponsiveness (BHR) to nonspecific stimuli and the increase in FEV1 in response to bronchodilators are both important hallmarks of asthma [1]. Therefore, it is tempting to regard the two phenomena as highly correlated, and several studies have used the response to bronchodilators as an indicator of BHR [17, 18]. We have found that there was no statistically significant relationship between $\triangle \mathrm{FEV} 1 \%$ init and airway responses to histamine or methacholine. This is in keeping with a number of studies which failed to show a correlation between BHR and the bronchodilator response to salbutamol $[19,20]$. It is likely that important differences are present in the mechanisms underlying both phenomena. Patients with irreversible airway obstruction exhibit significant bronchoconstrictor responses, whilst healthy subjects without BHR may reveal large bronchodilator responses [21]. Moreover, the observation that the bronchodilator response persists longer than the protective effect against bronchoconstrictor stimuli [3] adds further evidence to the view that diverse pathophysiological mechanisms are involved. Thus, in asthmatic subjects, the bronchodilator response should not be directly related to BHR.

In conclusion, in asthmatic subjects the degree of bronchodilatation achieved after a single $200 \mu \mathrm{g}$ dose of salbutamol is not affected by prior bronchoprovocation testing when enough time is allowed for the airways to recover spontaneously to prechallenge levels of forced expiratory volume in one second (FEV1). Thus evaluation of airway responsiveness by both bronchial provocation tests and bronchodilator testing can be assessed reliably within a few hours in asthmatic patients.

\section{References}

1. American Thoracic Society. Statements on standards for diagnosis and care of patients with chronic obstructive pulmonary disease (COPD) and asthma. Am Rev Respir Dis 1987; 136: 225-244.

2. Rijcken B, Schouten JP, Weiss ST, Speizer FE, van der Lende $\mathrm{R}$. The relationship of nonspecific bronchial responsiveness to respiratory symptoms in a random population sample. Am Rev Respir Dis 1987; 136: 62-68. 
3. Ahrens RC, Bonham AC, Maxwell GA, Weinberger MM. A method for comparing the peak intensity and duration of action of aerosolized bronchoprovocation with methacholine. Am Rev Respir Dis 1984; 129: 903-906.

4. Ahrens RC, Harris JB. Use of bronchial provocation with histamine to compare the pharmacodynamics of inhaled albuterol and metaproterenol in patients with asthma. $J$ Allergy Clin Immunol 1987; 79: 876-882.

5. van Essen-Zandvilet EEM, Kerrebijn KF. The effect of antiasthma drugs on bronchial hyperresponsiveness. Immunol Allergy Clin North Am 1990; 10: 483-501.

6. Cartier A, Malo J-L, Begin B, Sestier M, Martin RR. Time course of the bronchoconstriction induced by inhaled histamine and methacholine. J Appl Physiol 1983; 54: 821-826.

7. Long WM, Sprung CL, Fawal HE, et al. Effects of histamine on bronchial artery blood flow and bronchomotor tone. J Appl Physiol 1985; 59: 254-261.

8. Laitinen LA, Laitinen A, Widdicombe JG. Effects of inflammatory and other mediators on airway vascular beds. Am Rev Respir Dis 1987; 135: S67-S70.

9. Persson CGA. Plasma exudation in the airways: mechanisms and function. Eur Respir J 1991; 4: 1268-1274.

10. American Thoracic Society. Lung function testing: selection of reference values and interpretative strategies. $\mathrm{Am}$ Rev Respir Dis 1991; 144: 1202-1218.

11. Lewis RA. Therapeutic aerosols. In: Cumming G, Bonsignore C, eds. Drugs and the Lung. London, Plenum Publishing Co., 1984; pp. 63-86.

12. Chai H, Farr RS, Froehlich LA, et al. Standardization of bronchial inhalation challenge procedures. J Allergy Clin Immunol 1975; 56: 323-327.
13. Altman DG, Bland JH. Statistical methods for assessing agreement between two methods of clinical measurement. Lancet 1986; i: 307-310.

14. Gerritsen J, Koeter GH, Akkerboom HJ, Knol K. Recovery of FEV1 after histamine challenge in asthmatic children. Clin Allergy 1987; 17: 119-126.

15. Polosa R, Finnerty JP, Holgate ST. Tachyphylaxis to inhaled histamine in asthma: its significance and relationship to basal airways responsiveness. J Allergy Clin Immunol 1990; 86: 265-271.

16. Merkus PJFM, Eelkman-Rooda HM, van Essen-Zandvilet EEM, Duiverman EJ, Quanjer PH, Kerrebijn KF. Assessment of bronchodilatation after spontaneous recovery from histamine challenge in asthmatic children. Thorax 1992; 47: 355-359.

17. Kanner RE. The relationship between airways responsiveness and chronic airflow limitation. Chest 1984; 86: 54-57.

18. Vollmer WM, Johnson LR, Buist AS. Relationship of response to a bronchodilator and decline in FEV1 in population studies. Am Rev Respir Dis 1985; 132: 11861193.

19. Postma DS, de Graaf-Breederveld N, Koeter GH, Sluiter HJ. The relationship between reversibility and hyperreactivity. Eur J Respir Dis 1986; 68: 483-485.

20. Bibi H, Montgomery M, Paterkamp H, Cherniack V. Relationship between response to inhaled salbutamol and methacholine bronchial provocation in children with suspected asthma. Pediatr Pulmonol 1991; 10: 244-248.

21. Loren ML, Leung PK, Cooley RL, et al. Irreversibility of obstructive changes in severe asthma in childhood. Chest 1978; 74 : 126-128. 